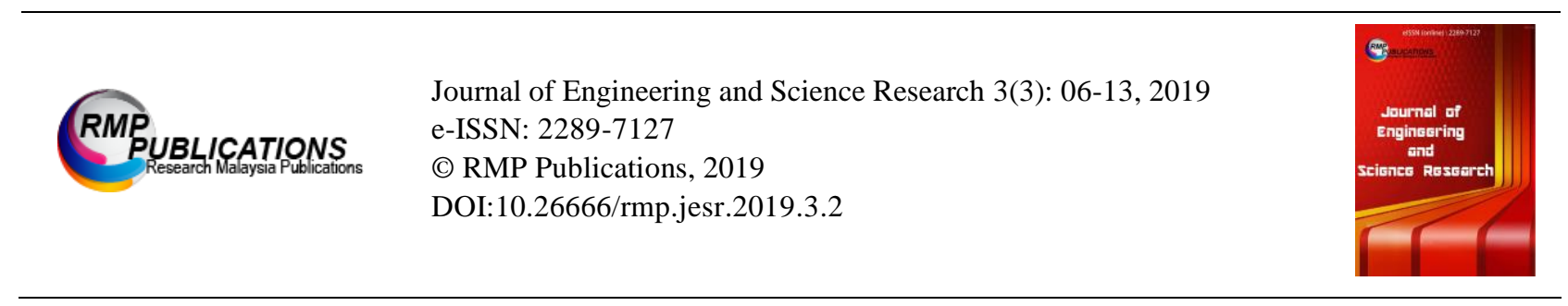

\title{
Landsat-Based Drought Phenomenon Evaluation of Cassava and Sugar cane in Northeast Thailand
}

\author{
Tenanile Dlamini and Veeranun Songsom \\ Faculty of Technology and Environment, Prince of Songkla University, Phuket Campus \\ tenanilend@gmail.com, veeranun.s@phuket.psu.ac.th
}

\begin{abstract}
Northeast Thailand is a predominantly agriculture-based region yet it suffers from drought which threatens the people's livelihood. The region is the largest producer of sugar cane and cassava in the country which are classified as high-value, food and energy crops. Thailand ranks first and third in the world in terms of exporting cassava and sugar cane respectively. Unfortunately, when compared to other regions, the northeast receives the least attention in terms of agricultural research yet it is the most vulnerable part of the country. As such, the goal of this study was to assess agricultural drought in the region pertaining to sugar cane and cassava farming over twelve years (2004 to 2015) relative to the climatic conditions. Normalized Difference Vegetation Index (NDVI)based Vegetation Condition Index (VCI), derived from Landsat 5 and 8 satellites (30 meters' resolution) was used as a determinant of agricultural drought. Precipitation and temperature (0.25-degree resolution) data were sourced from GLDAS-2 Noah model products. Temporal-VCI indicated that the major agricultural drought periods for both crops were 2004, 2005, 2007, 2008, 2009 and 2011. A significant improvement in the crops' condition was noted in 2014 and 2015. Similarly, spatial-VCI showed an increase in VCI for 2014 and 2015 despite these being major meteorological drought years. This supports the premise that the region has made efforts to curb the effects of drought on agriculture. However, continuous monitoring of drought using different physical indicators is necessary for further development of effective solutions and sharpening of the currently existing measures.
\end{abstract}

Keywords: VCI, Landsat, drought, Thailand, crops

\section{INTRODUCTION}

Drought and the resultant food insecurity are ranked high on the priority list of humanitarian aid organizations [1]. The northeast of Thailand is one region that has not been spared from the effects of droughts. A lot of provinces in the region are amongst the least privileged in the country. It relies heavily on agriculture yet has unfavorable environmental and climatic conditions, and limited irrigation resources [2]. The reservoirs are shallow, soils are poor and have low water holding capacity [3]. The climate is also characterized by highly variable rainfall. These conditions have led to a myriad of problems including severe water shortages, crop failure and food insecurity [4]. One approach to overcoming this is to monitor, assess and comprehend the behavior of agricultural drought in the area. Cassava and sugar cane [5] are amongst favorable crops cultivated at an extensive scale in the northeast, ranking highly in the selected provinces for this study; Khon Kaen, Chaiyaphum and Nakhon Ratchasima.

Agricultural drought is defined by and Belal et al. (2014) [6] as a decline in soil moisture resulting in crop failure. The implementation of remote sensing technology to manage disasters has proven to be reliable in the assessment of hazards and risk management [6]. Its application to drought monitoring provides the understanding of the spatial and temporal extent of the disaster. In turn, this provides the opportunity for enhancing early warning systems [7] and subsequently improving mitigation measures [1]. Remote sensing indices such as the Normalized Difference Vegetation Index (NDVI) and Vegetation Condition Index (VCI) are recognized globally as agricultural drought indicators [8]. The objectives of

Corresponding Author: Tenanile Dlamini, Prince of Songkla University, Phuket Campus, Kathu District, Phuket 83120, Thailand, email:tenanilend@gmail.com 
this study were to; Display spatial-VCI during major meteorological drought years to assess whether there is any correspondence with agricultural drought; Ascertain the rainfall and temperature trends for the study period; Use monthly crop-VCI for sugar cane and cassava to determine the prevailing severity of agricultural drought for each year from 2004 to 2015.

\section{STUDY AREA}

The northeast region is located at $14^{\circ} 14^{\prime}$ to $18^{\circ}$ $27^{\prime} \mathrm{N}$ latitude and $101^{\circ} 15^{\prime}$ to $105^{\circ} 35^{\prime} \mathrm{E}$ longitude. According to the Koppen climate classification, the northeast region is considered to have a tropical savannah climate [9]. The region undergoes 3 seasons; summer, rainy and winter seasons [10]. February to May is the summer season with high temperatures reaching beyond $30^{\circ} \mathrm{C}$ during the hottest month (April) and dry weather conditions with barely any rainfall. The rainy season commences from May to October, receiving average rains ranging between $1800 \mathrm{~mm}$ to $2800 \mathrm{~mm}$ [10]. The rain is irregular and has a high variance. Rains decrease rapidly in late October and early November giving way to the winter season. The rest of the period between October and February is the winter season. Mean annual temperatures in the northeast range between $18.7^{\circ} \mathrm{C}$ and $35.2{ }^{\circ} \mathrm{C}$. However, the region has distinct seasonal temperature variations due to its generally high altitude [11].

Sugar cane and cassava are popular for their ability to withstand drought but may still be affected to a certain extent. In addition to that, their products are of high value providing a stable income for farmers [12]. Figure 1 shows the areas which exclusively grow sugar cane and cassava. The onset of rains is a signal for the planting of cassava. It is grown in all the provinces of the region with Nakhon Ratchasima being the largest grower [13], followed by Chaiyaphum. Farmers in the region usually plant cassava during between May and June (figure 2). The growing period is between 9 to 12 months [13]. The end of the rainy season implies readiness for the planting of sugar cane. It is grown in 16 out of 20 provinces in the region including Khon Kaen, Chaiyaphum and Nakhon Ratchasima. The planting time is between October and November (figure 2). It is harvested after 10 to 14 months [13].

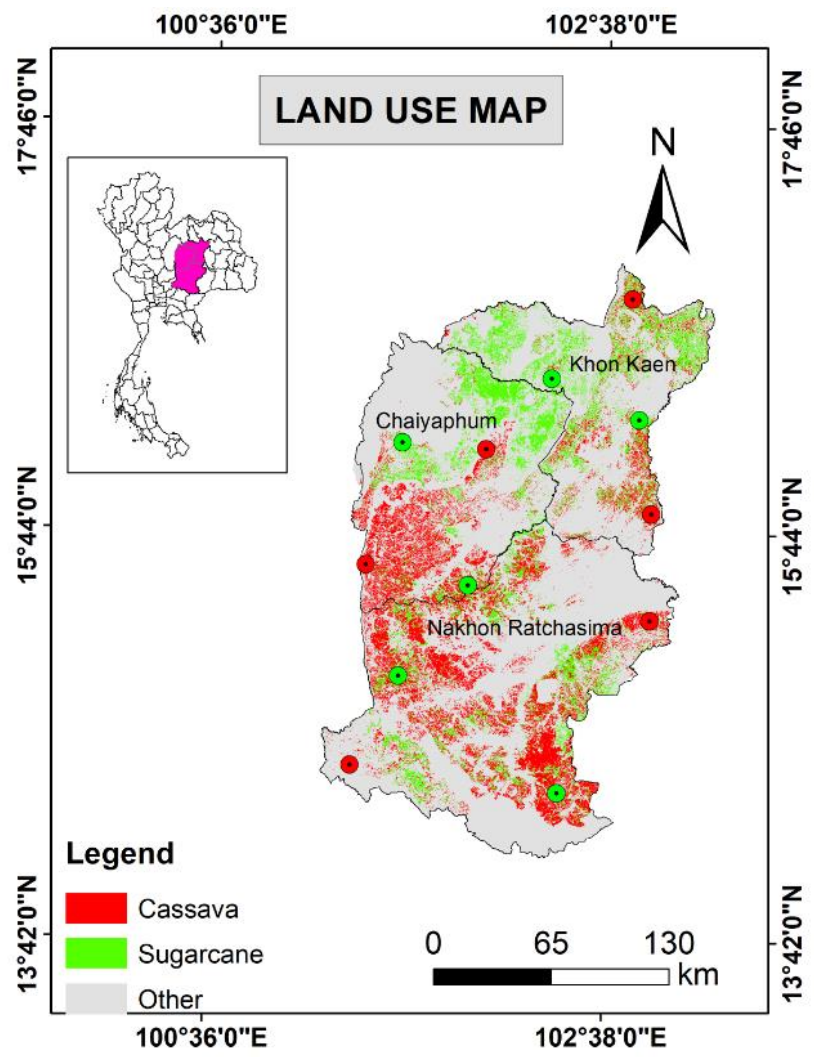

Fig. 1 Land use map of the study area for 2017 showing cassava and sugarcane fields with selected points and Thailand map (inset) 


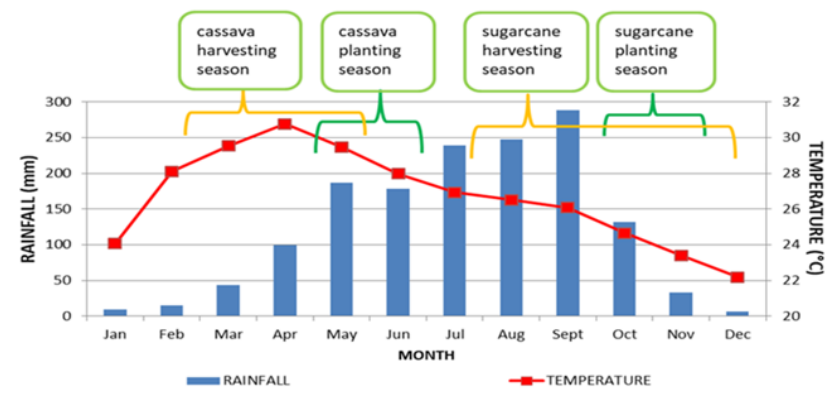

Fig. 2 Average monthly rainfall and temperature for the study area from 2004 to 2015

\section{MATERIALS AND METHODS}

\section{A. Data Acquisition}

Landsat 5 Multispectral Scanner (MSS) was used to obtain vegetation data from 2004 to 2011 and Landsat 8 Operation Land Imager (OLI) / Thermal Infrared Sensor (TIRS) data from 2013 to 2015, 16 days' temporal resolution, and $30 \mathrm{~m}$ spatial resolution from Collection 1 Level-1 data products

Rainfall and temperature data was acquired from NASA archives, GLDAS-2 Noah Land Surface Model data products. Data with a monthly temporal resolution and a spatial resolution of 0.25 degrees was utilized.

\section{B. Data Processing}

A set of 12 points (Fig. 1) were selected within the study area (Khon Kaen, Nakhon Ratchasima, and Chaiyaphum) for data extraction purposes. This was done on the bases of identifying those areas where land use had not changed over time, pertaining to exclusive farming of sugarcane and cassava using Land use land cover maps (LULC). In each province, a set of 4 points was picked with one couple representing sugar cane, another representing cassava.

Measuring of monthly NDVI was conducted utilizing the reflectance of red (R) and near-infrared (NIR) bands [14] as follows;

$$
N D V I=(N I R-R) /(N I R+R)
$$

Thereafter, VCI was calculated based on NDVI. VCI is more efficient than NDVI in assessing drought-related vegetation stress in terms of the different parameters of drought including; the inception of the drought, duration, intensity, and severity. As the foundation of VCI is vegetation, it is mainly useful during the growing season [8]. It is calculated as follows:

$$
V C I=\frac{N D V I_{i}-N D V I_{\min }}{N D V I_{\max }-N D V I_{\min }} \times 100
$$

$N D V I_{i}$ represents the NDVI of pixels for a specific period under study $N D V I_{\max }$ and $N D V I_{\min }$ are the largest and smallest NDVI values for a specific time respectively. They represent the best and worst vegetation conditions. The numerator of the equation shows vegetation growth hence a small value is an indication of less growth [9]. VCI values range between 0 and 100 whereby lower values indicate poor vegetation condition and high values indicate healthy vegetation.

\section{Data Analysis}

Spatio-temporal data of VCI was displayed for; 2004, 2005, 2010, 2014 and 2015 to show the severity and extent of agricultural drought during these major meteorological drought years. Temporal variations in average monthly rainfall and temperature from 2004 to 2015 were displayed graphically to determine the prevailing conditions at the time of interest. Graphs were also used to display the temporal variations in crop-VCI for sugar cane and cassava. This served to determine common agricultural drought years based on comparing and contrasting VCI values. VCI values range from 0 to 100 , with categories indicating the drought intensity as shown in Table 1. Lastly, the area of sugar cane and cassava fields was calculated using data from LULC maps. This was done to establish if there has been an increase or decrease in the rate of agriculture over time. 
Tenanile and Veeranun / Journal of Engineering and Science Research,3(3) 2019, Pages: 06-13

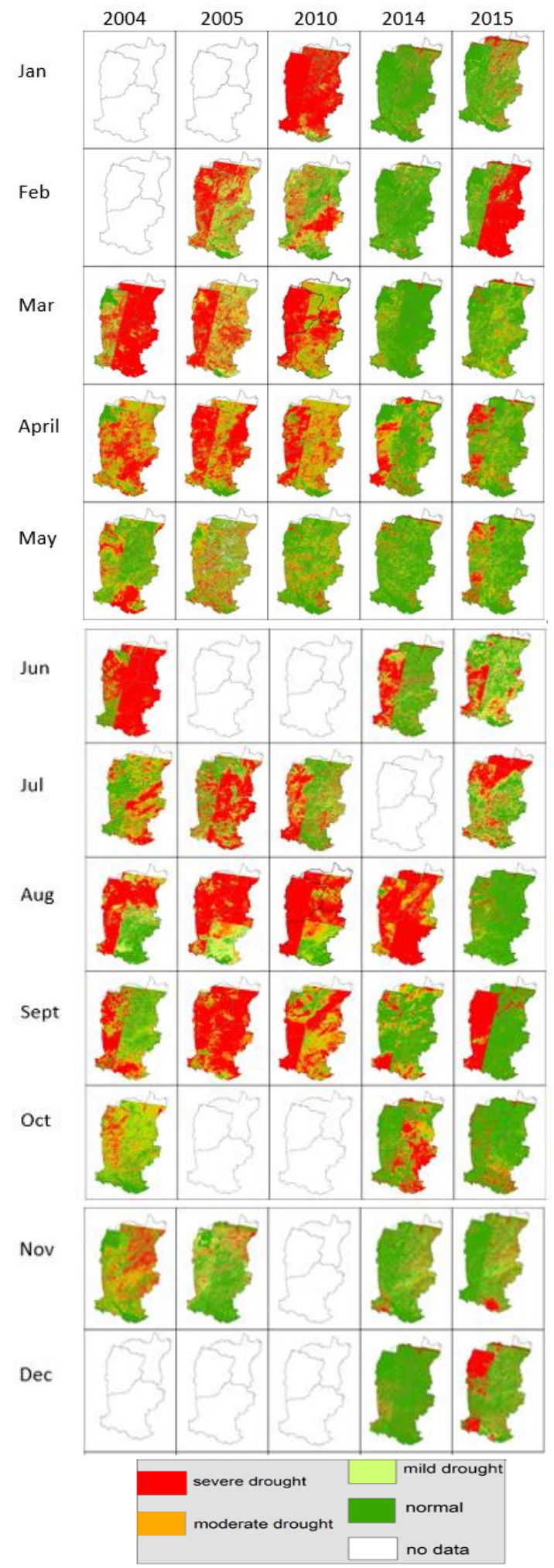

Fig. 3 Spatio-temporal patterns of VCI for 2004, 2005, 2010, 2014 and 2015 
Table 1 VCI criteria for drought phenomenon; [14]

\begin{tabular}{|c|c|}
\hline VCI & Level \\
\hline$\geq 70$ & Normal \\
\hline $50 \leq \mathrm{VCI}<70$ & Mild drought \\
\hline $30<\mathrm{VCI}<50$ & Moderate drought \\
\hline$\leq 30$ & Severe drought \\
\hline
\end{tabular}

\section{RESULTS AND DISCUSSION}

\section{A. Spatio-temporal patterns of VCI for major meteorological drought years}

Figure 3 shows the spatial patterns of VCI during major meteorological drought years; 2004, 2005, 2010, 2014 and 2015. It is evident that vegetation in the area was worst affected during; 2004, 2005 and 2010. These years were dominated by moderate to extreme agricultural drought. On the other hand, the years 2014 and 2015 depicted improved vegetation conditions. The area was largely exposed to mild agricultural drought and normal conditions. Notably, the two latter years do not correspond to the meteorological drought conditions that prevailed at the time. The notable change in VCI distribution suggests an increase in vegetation cover and improved health. This includes the dry season (October to April) which is characterized by extreme dryness in the northeast. For the latter years, VCI during this season mainly indicated healthy vegetation. There was no distinct pattern in the distribution of VCI based on the seasons.

Possible reasons for the improvement in agricultural drought conditions over the years can be attributed to the main role played by the Thailand government. To lessen the effects of agricultural drought, previous studies concur that the region receives continuous government support aimed at improving agriculture. This includes investing in irrigation infrastructure, making irrigation widely available. This has enabled farming even during the dry season. Government has developed policies inducing the compensation of farmers in cases of crop losses due to the annual flooding of lowland areas. This practice has encouraged the cultivation of land which would otherwise have not been cultivated. Farmers who had abandoned agriculture due to debts incurred as a result of crop loss have also resumed practice. The enforcement of forest conservation guidelines has also seen an increase in vegetated areas, leading to farmers having trees even in their fields.

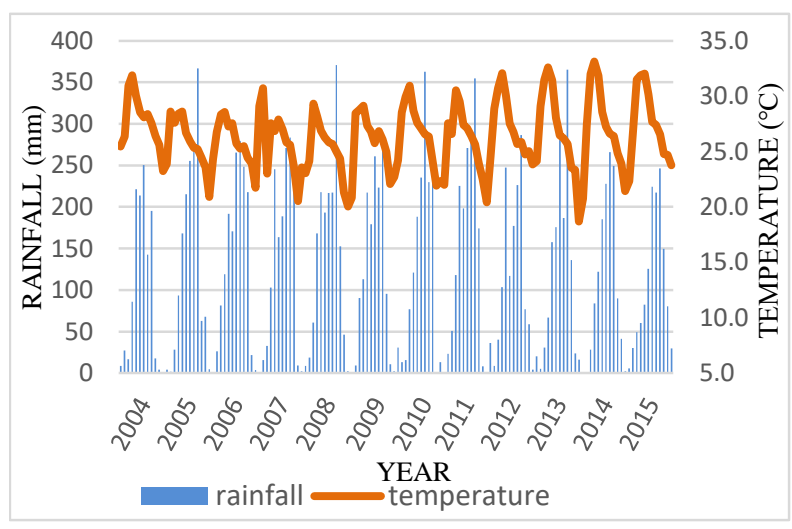

Fig. 4 Average monthly rainfall and temperature for the study area from 2004 to 2015

\section{B. Rainfall and Temperature}

The general temperature trend in Figure 4 depicts warm to hot conditions for the better part of each year. There was also an increase in the average level of warm conditions as time progressed. This can be seen as maximum temperatures soared above $30{ }^{\circ} \mathrm{C}$ from 2012 to 2015. Previous years show average maximums below $30^{\circ} \mathrm{C}$ but well above $25^{\circ} \mathrm{C}$, with the exception of 2004 which was also considerably high. In terms of precipitation, there was high variation in 


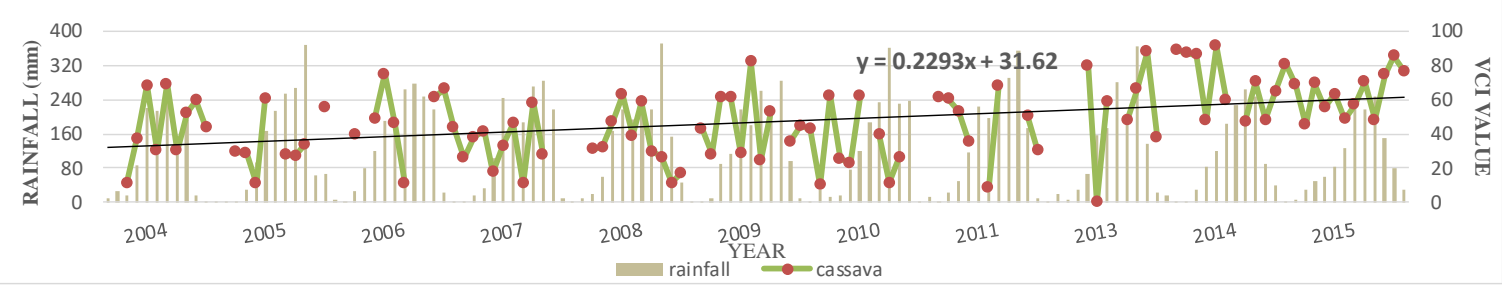

Fig. 5 VCI time series for cassava and VCI trend line from 2004 to 2015

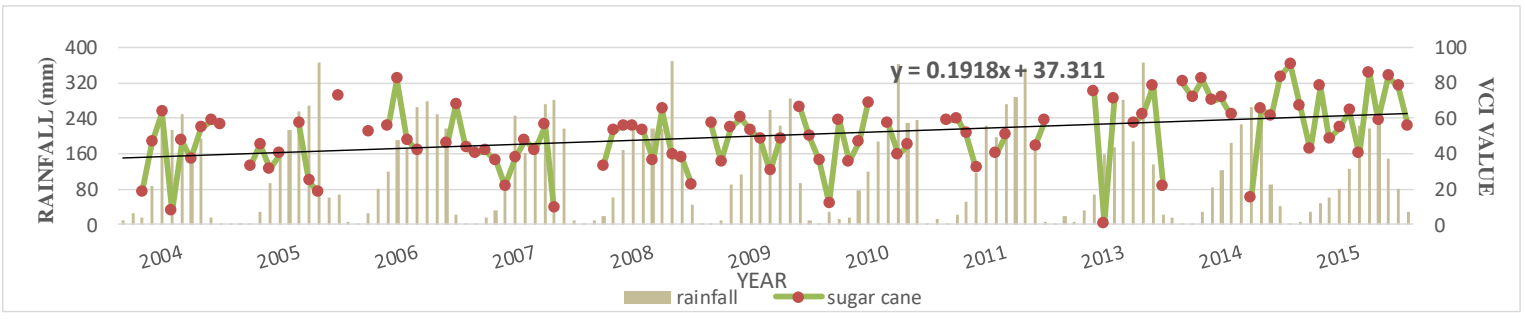

Fig. 6 VCI time series for sugar cane and VCI trend line from 2004 to 2015

received any rainfall as indicated by monthly values below $25 \mathrm{~mm}$ and high values of more than $350 \mathrm{~mm}$. The years 2004 and 2015 suffered short as they had maximums below $250 \mathrm{~mm}$ during the wet season. The gap between 2004 and 2005 in contrast to other years signals the late pick-up of rains.

\section{Temporal variations of VCI for cassava and sugar cane}

Figure 5 and figure 6 show the average monthly crop-VCI and monthly rainfall for each year of the period of study. From 2004 to 2013 there were notably lower VCI values for both crops, mainly ranging between 0 and 60 . Values indicate that every year the area experiences periods of aridity ranging from moderate to severe. The major agricultural drought years were classified as those which consisted of 4 or more months of severe conditions. For cassava these were; 2004, 2005, 2007, 2008, 2009, 2010 and 2011. Sugar cane was mainly exposed to agricultural drought during; 2004, 2005, 2007, 2008, 2009, and 2011. Generally, there was a consensus between both sets of time. From 2014 to 2015, the measurements of both crops showed an improvement in agricultural drought conditions compared to the previous years as the average values were from 40 to 90 . This is in spite of the insignificant variation in rainfall. The two years mainly had mild agricultural drought to normal conditions. This is in agreement with the spatial-VCI in figure 3.

The positive slopes of the equations for the trend lines also confirm remediation of the crops' condition. Although the performance of the crops was better improvement than sugar cane $(0.1918)$ over time. It is important to note that low VCI values are not always an indication of agricultural drought. Periods of harvesting, poor fertilization practices and floods leading to crop destruction can contribute to low VCI values. The northeast is largely covered by sandy soils with low fertility. The area also experiences flooding between August and September due to tropical cyclones brought about by the southwest monsoon. The year 2011 was the worst in terms of flooding and notably, this is registered as an agricultural drought year based on the temporal VCI results yet it is not the actual case.

\section{Expansion of cassava and sugar cane fields}

An investigation into land use pertaining to cassava and sugar cane farming also provides evidence of expansion in crop agriculture over time. From the data presented in figures 7,8 and 9 it is clear that the area of cassava and sugar cane farms increased. In Chaiyaphum, cassava and sugar cane were spread over an area of $765.83 \mathrm{~km}^{2}$ and $718.54 \mathrm{~km}^{2}$ in 2006 to $1787.72 \mathrm{~km}^{2}$ and $1460.08 \mathrm{~km}^{2}$ in 2015 respectively. In Khon Kaen, both cassava and sugar cane was grown at a scale of $379.50 \mathrm{~km}^{2}$ and $761.92 \mathrm{~km}^{2}$ in 2006 , extending to $680.51 \mathrm{~km}^{2}$ and $1842.40 \mathrm{~km}^{2}$ in 2015 respectively. Nakhon Ratchasima, which is a main grower of cassava also experienced an increase of $287.27 \mathrm{~km}^{2}$ in cassava fields between 2007 and 2015 whilst sugar cane fields increased by $594.77 \mathrm{~km}^{2}$. Although none of these crops is a staple, their success is due to diverse uses, high demand, secure markets, and tolerance to unfavorable environmental conditions. 
Cassava has been proven to be drought-tolerant, low maintenance and suitable to grow in variable soil conditions. Sugar cane also has the ability to perform well under rain-fed conditions and poor soils.

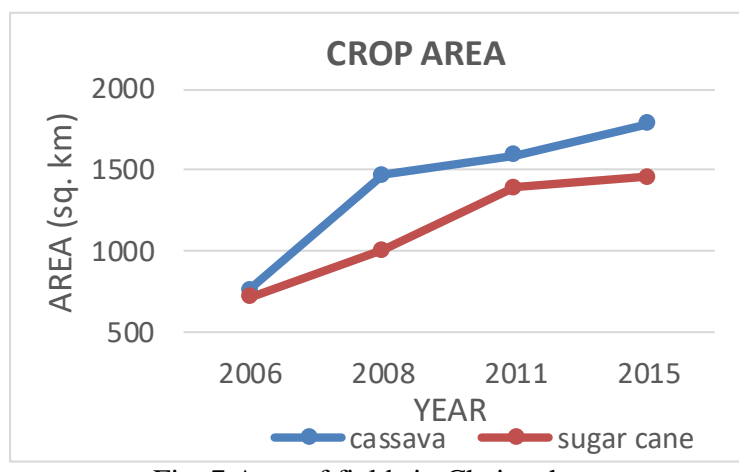

Fig. 7 Area of fields in Chaiyaphum

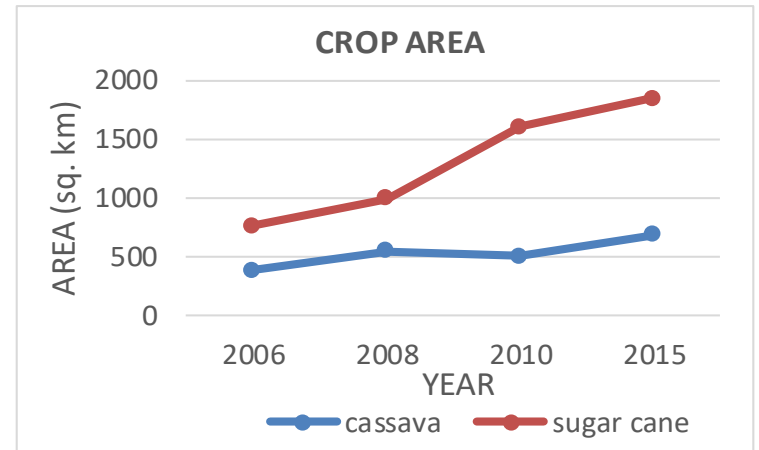

Fig. 8 Area of fields in Khon Kaen

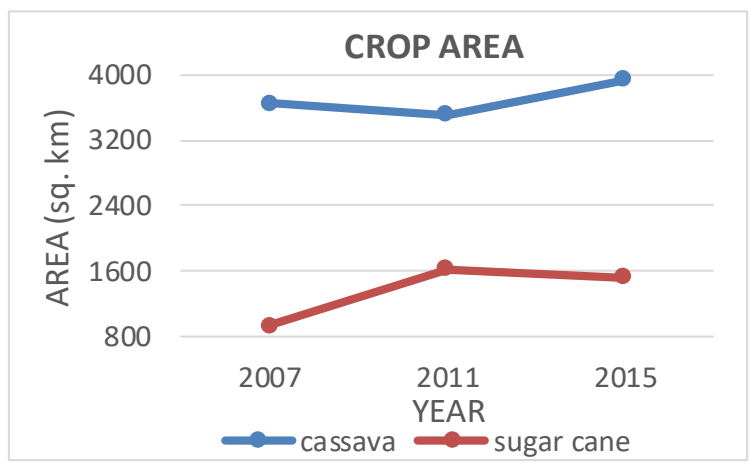

Fig. 9 Area of fields in Nakhon Ratchasima

\section{CONCLUSION}

$\mathrm{VCI}$ is a useful index for analyzing agricultural drought based on vegetation condition. The Landsat 5 and 8 imageries are well-suited for monthly analysis of drought patterns due to their 16 days' re-visit time. However, their use is limited under heavy cloud cover. In the case of the study, VCI was able to highlight the vegetation status in terms of spatiality and temporality. Though that may be the case, it was also evident that low VCI values do not guarantee agricultural drought years as other factors may contribute to such. Although agricultural drought emanates from meteorological drought, there was no correspondence between some years as the area has implemented drought-risk reduction measures. Consequently, the crops' condition indicated less severe agricultural drought conditions as time progressed.

\section{ACKNOWLEDGEMENTS}

Acknowledgment is due to the Faculty of Technology and Environment, Prince of Songkla University, Phuket Campus for academic support and Land Development Department, Thailand Government for LULC maps. Special thanks to the Thailand International Cooperation Agency for academic funding.

\section{REFERENCES}

[1] Enenkel M., See L., R. Bonifacio R., V. Boken, N. Chaney, Vinck P. and Anderson M. 2015. Drought and food security - Improving decision-support via new technologies and innovative collaboration. Glob. Food Sec., 4, 51-55. doi:10.1016/j.gfs.2014.08.005

[2] Choenkwan, S., Fox, J. M. and Rambo, A. T. 2014. Agriculture in the Mountains of Northeastern Thailand: Current Situation and Prospects for 
Development. Mt. Res. Dev., 34(2), 95-106, May 2014. doi:10.1659/MRD-JOURNAL-D-13-00121.1

[3] Grandstaff, T. B., Grandstaff, S., Limpinuntana, V. and Suphanchaimat N. 2008. Rainfed revolution in Northeast Thailand. Southeast Asian Stud., 46(3), 289-376. Available: https://kyotoseas.org/pdf/46/3/460301.pdf

[4] Richter, P., Ouyyanont, K. 2017. Rural Thailand: Change and Continuity. Trends in Southeast Asia \#8)", Singapore: ISEAS-Yusof Ishak Institute. J. Popul. Soc. Stud., 25(1), 8. doi:10.14456/jpss.2017.7

[5] Damen B. 2010. BEFS Thailand: Key results and policy recommendations for future bioenergy development. working paper. FAO, Rome. Available: http://www.fao.org/docrep/013/i1745e/i1745e.pdf

[6] Belal A. -A., El-Ramady, H. R., Mohamed E. S., and Saleh A. M. 2014. Drought risk assessment using remote sensing and GIS techniques. Arab. J. Geosci., 7(1), 35-53. Available: https://link.springer.com/article/10.1007/s12517012-0707-2

[7] AghaKouchak A., Farahmand A., Melton F. S., Teixeira J., Anderson M. C., Wardlow B. D. and Hain C. R. 2015. Remote sensing of drought: progress, challenges and opportunities. Rev. Geophys., 53(2), 452-480. doi: 10.1002/2014RG000456

[8] Dutta D., Kundu A., Patel N. R., Saha S. K. and Siddiqui A. R. 2015. Assessment of agricultural drought in Rajasthan (India) using remote sensing derived Vegetation Condition Index (VCI) and Standardized Precipitation Index (SPI). Egypt. J.
Remote Sens. Sp. Sci., 18(1), 53-63. doi: 10.1016/j.ejrs.2015.03.006.

[9] Awata E. N., Agata Y. N., Asaki A. S., Wama K. I. and Akuratani T. S. 2005. Mapping of climatic data in Northeast Thailand: Rainfall. Tropics, 14(2), 191201. doi: 10.3759/tropics.14.191

[10] Phien J. N., Arbhabhirama A. and Sunchindah A. 2009. Rainfall distribution in northeastern Thailand. Hydrol. Sci. Bull., 25(2), 167-182. doi $10.1080 / 02626668009491921$

[11] Thailand Meteorological Department 2015. The Climate of Thailand (1981-2010). Available: https://www.tmd.go.th/en/archive/thailand_climate. pdf

[12] Ekasingh B., Sungkapitux C., Kitchaicharoen J. and Suebpongsang P. 2007. Cassava and Sugarcane. In The Development of Competitive commercial agriculture in the Northeast of Thailand, 1950-2006: A review, 63 - 93. The Multiple Cropping Centre, Faculty of Agriculture, Chiang Mai University (Thailand)

[13] Kheoruenromne I., Suddhiprakarn A., and Kanghae P. 1998. Properties, Environment and Fertility Capability of Sandy Soils in Northeast Plateau, Thailand. The Kasetsart Journal of Natural Sciences, 373, 355-373. Available: http://kasetsartjournal.ku.ac.th/kuj_files/2008/A080 4281126029596.pdf

[14] Qian X., Liang L., Shen Q., Sun Q., Zhang L., Liu Z. and Qin Z. 2016. Drought trends based on the VCI and its correlation with climate factors in the agricultural areas of China from 1982 to 2010. Environ. Monit. Assess., 88(11), 639. doi: 10.1007/s10661-016-5657-9 